\title{
POSSIBILIDADES DE SIGNIFICAÇÃO DE COR EM IMAGENS ON-LINE: RECONTEXTUALIZAÇÃO DO DISCURSO CIENTÍFICO E INTERDISCURSIVIDADE
}

\author{
COLOUR'S MEANING POSSIBILITIES IN ONLINE IMAGES: \\ RECONTEXTUALIZATION OF SCIENTIFIC DISCOURSE AND \\ INTERDISCURSIVITY
}

\author{
Fatima Andreia Tamanini ADAMES ${ }^{1}$ \\ UFSM- Universidade Federal de Santa Maria
}

\begin{abstract}
RESUMO: A recontextualização, bem como as concepções de texto e prática discursiva desenvolvidas por Fairclough na Análise Crítica do Discurso, estão conectadas ao conceito de interdiscursividade. Com base nessa abordagem interdisciplinar, na Gramática do Design Visual e na Semiótica Social da Cor, estudo como um artigo científico é recontextualizado em notícias on-line por meio da análise interdiscursiva das possibilidades de significação de cor das imagens em termos de modalidade visual. Todas as cores são cores em sistemas de cor que podem ser definidos através de usos específicos de traços distintivos. Na "gramática da cor", há regularidades que surgem a partir dos interesses dos produtores de sentido. E na abordagem de traços distintivos para a Semiótica da Cor, a instância de uma cor é analisada como potenciais de significado. Neste artigo, as imagens da ciência apresentam baixa modulação e modalidade abstrata, e as imagens do jornalismo on-line de popularização da ciência apresentam alta modulação e modalidade naturalística em diferentes graus, sugerindo o estilo dessas esferas. Além disso, as imagens altamente naturalísticas têm parâmetros distintivos iguais, representando um esquema de cores relacionado a essa modalidade.
\end{abstract}

PALAVRAS-CHAVE: Gênero discursivo notícia de popularização da ciência on-line; Análise Crítica do Discurso; Interdiscursividade; Multimodalidade; Semiótica Social da Cor.

\begin{abstract}
The recontextualization, as well as the conceptions of text and discursive practice developed by Fairclough in Critical Discourse Analysis, is connected to the concept of interdiscursivity. Based on this interdisciplinary approach, on the Grammar of Visual Design and on the Colour Social Semiotics, I study how a scientific paper is recontextualized in online news through the interdiscursive analysis of color's meaning possibilities of the images in terms of visual modality. All colours are colours in colour systems which can be defined on the basis of specific uses of distinctive features. In the "colour grammar", there are regularities that arise from the interests of producers of meaning. And in distinctive features approach to the Semiotics of Colour, the instance of a colour is analyzed as meaning potentials. In this paper, the images from science show low modulation and abstract modality, and the images from online journalism of science popularization show high modulation and naturalistic modality in different degrees, suggesting the style of these

\footnotetext{
${ }^{1}$ Doutoranda no Programa de Pós-Graduação em Letras da Universidade Federal de Santa Maria (PPGL/UFSM) e pesquisadora do Laboratório de Ensino e Pesquisa de Leitura e Redação (LabLER), sob a orientação da Professora Dra. Désirée Motta-Roth.
} 
spheres. In addition, the highly naturalistic images have the same distinctive parameters, representing a color scheme related to this modality.

KEYWORDS: Discursive Genre Popularization News of Online Science; Critical Discourse Analysis; Interdiscursivity; Multimodality; Color Social Semiotics.

\section{Introdução}

A popularização da ciência pode ser definida como um modo de circulação do conhecimento por recontextualização de textos científicos (MOTTA-ROTH; LOVATO, 2011, p. 253 com base em BERNSTEIN, 1996). Esses textos recontextualizados muitas vezes são artigos científicos previamente publicados em revistas especializadas. E essa recontextualização quase sempre acontece na mídia de massa. Nesse caso, há um entrecruzamento entre as esferas de atividade da ciência e da mídia, duas diferentes ordens discursivas (MOTTA-ROTH; SCHERER, 2012, p. 640). De acordo com Norman Fairclough (2003, p. 51), a recontextualização, bem como as concepções de texto e prática discursiva desenvolvidas na Análise Crítica do Discurso (doravante ACD), estão conectadas ao conceito de intertextualidade. $\mathrm{O}$ termo intertextualidade, cunhado por Julia Kristeva a partir da noção bakhtiniana de dialogismo, refere-se a ambas: intertextualidade manifesta e intertextualidade constitutiva ou interdiscursividade. Essa última, meu interesse neste trabalho, é a categoria analítica que delimita as escolhas metodológicas relacionadas ao meu objetivo geral: estudar, por meio da identificação de marcas interdiscursivas, o processo de recontextualização do discurso da esfera científica pelo discurso da esfera midiática, configurando-se em um processo de popularização da ciência.

Tomando como referência principal os pressupostos teóricos para análise multimodal da Gramática do Design Visual (doravante GDV) de Kress e Van Leeuwen (2006) e da Semiótica Social da Cor proposta por Kress e Van Leeuwen (2002) e Van Leeuwen (2011), bem como da Semiótica Social (VAN LEEUWEN, 2005) e da abordagem interdisciplinar da ACD (FAIRCLOUGH, 1985; 1995; 2000; 2001; 2003; 2006), tenho por objetivo específico verificar como um artigo científico é recontextualizado na mídia jornalística digital por notícias on-line por meio da análise interdiscursiva de cor em suas imagens. Mídia digital é um formato de mídia eletrônica onde os dados são armazenados em formato digital, de maneira oposta ao formato analógico, podendo referir-se ao aspecto técnico da armazenagem e transmissão da informação, ou ao produto final (LOTZ, 2007, p. 53-54). On-line, por sua vez, é um termo genérico que descreve acesso, recuperação ou disseminação de informação digital (WARD, 2007, p. 9).

A análise interdiscursiva é efetuada pela verificação das possibilidades de significação de cor por meio de traços distintivos (KRESS; VAN LEEUWEN, 2002; VAN LEEUWEN, 2011) em termos de modalidade visual (VAN LEEUWEN, 2005). A modalidade refere-se a significados textuais identificacionais, conforme a ACD, ou à metafunção interpessoal, segundo a Gramática Sistêmico-Funcional (doravante GSF). A GSF, na qual está apoiada a Linguística Sistêmico-Funcional (doravante LSF) desenvolvida por Michael Halliday, bem como a GDV, embasada em seus pressupostos, são usadas como ferramentas analíticas na ACD. A função interpessoal/identificacional está relacionada ao estilo do discurso, uma ordem que representa identidades tanto linguisticamente como semioticamente (FAIRCLOUGH, 2003, p. 41).

As imagens do corpus são veiculadas em um artigo científico disponibilizado no meio digital e em notícias de popularização da ciência oriundas de diferentes sites jornalísticos que recontextualizam esse mesmo discurso científico. O estudo ganha relevância principalmente porque notícias mais bem editadas ou com maior apelo popular obtêm Disponível em: http://seer.fclar.unesp.br/casa 
destaque na mídia, com, muitas vezes, uma imagem justificando a veiculação de determinado assunto (IVANISSEVICH, 2005, p. 20-21). Conforme Kress e Van Leeuwen (2006, p. 47), arranjos visuais reproduzem arranjos da realidade vinculados aos interesses das instituições sociais em que as imagens são produzidas, circuladas e lidas. E na gramática e na "gramática da cor", há regularidades que surgem a partir desses interesses dos produtores de sentido (KRESS; VAN LEEUWEN, 2002, p. 345).

Partindo do princípio de que somos letrados se formos capazes de "atribuir sentidos a mensagens oriundas de múltiplas fontes de linguagem" e "produzir mensagens incorporando múltiplas fontes de linguagem" (DIONÍSIO, 2005, p. 131), dominando escrita e leitura multimodalmente e multimidiaticamente, destaco no presente artigo a abordagem de traços distintivos para a Semiótica da Cor postulada por Kress e Van Leeuwen (2002) e Van Leeuwen (2011). Para Kress e Van Leeuwen (2002, p. 366), todas as cores são cores em sistemas de cor que podem ser definidos com base em usos específicos de traços distintivos. Essa abordagem permite analisar cor como valores em dez escalas, como potenciais de significado ou potenciais metafóricos (VAN LEEUWEN, 2011, p. 60-65). Metáforas, que são abstrações, também "moldam significados identificacionais em textos" (RAMALHO; RESENDE, 2011, p. 146) e, por consequência, relacionam-se ao estilo discursivo.

Assim, na primeira parte deste trabalho, defino meu campo de investigação: o processo de recontextualização do discurso não verbal de um artigo científico pelo discurso não verbal de notícias on-line, evidenciado por marcas interdiscursivas. Na sequência, reviso a teoria aplicada ao corpus, sistematizo a metodologia e discuto os dados levantados.

\section{Gênero discursivo notícia de popularização da ciência on-line}

De acordo com Mikhail Bakhtin (1997, p. 279), a utilização da língua efetua-se na forma de enunciados que emanam de esferas de atividade humana, refletindo as condições específicas e as finalidades de cada uma dessas esferas, não só por seu conteúdo temático e por seu estilo (seleção operada nos recursos lexicais, fraseológicos e gramaticais da língua), mas, sobretudo, por sua construção composicional. Essas três dimensões "fundem-se indissoluvelmente no todo do enunciado" (BAKHTIN, 1997, p. 279). Todos os enunciados dispõem de uma "forma padrão e relativamente estável de estruturação do todo", que são os gêneros discursivos (BAKHTIN, 1997, p. 301), marcados pela especificidade de uma dada esfera de comunicação (BAKHTIN, 1997, p. 279).

Na esfera científica, "ciência" significa "conhecimento" (FERREIRA, 1986 apud MOTTA-ROTH; MARCUZZO, 2010, p. 512), é o conhecimento de qualquer fenômeno através da observação, identificação, descrição, investigação e explicação desse fenômeno com base em um paradigma vigente (MOTTA-ROTH, 2009) ${ }^{2}$. E as práticas discursivas são constitutivas do conhecimento cuja transformação em ciência está ligada diretamente a elas (FAIRCLOUGH, 2001, p. 62 com base em FOUCAULT, 1994). Entretanto, tradicionalmente associado a centros acadêmicos de investigação, o discurso da ciência também circula em outras esferas de atividade ou ordens do discurso, como na esfera midiática jornalística, quando de sua popularização. As ordens do discurso referem-se ao conjunto de práticas discursivas associadas a uma instituição social e às relações entre essas práticas discursivas (FAIRCLOUGH, 2006, p. 170). Na prática discursiva do jornalismo científico, por exemplo, jornalistas mediam a interação entre cientistas e um público não especialista, articulando

\footnotetext{
2 "Um paradigma pode ser definido como problemas e soluções modelares, fornecidos por pesquisas universalmente aceitas, a uma comunidade de profissionais". (KUHN, 1962/1970, p. viii apud MOTTA-ROTH; MARCUZZO, 2010, p. 512).
}

Disponível em: http://seer.fclar.unesp.br/casa 
discursos que ultrapassam o limite institucional científico (BEACCO et al., 2002, p. 282). Logo, a popularização da ciência é um processo de difusão do conhecimento, em que um evento discursivo é atualizado em outro evento discursivo associado a outra instituição social.

$\mathrm{Na}$ abordagem tridimensional da ACD, destacada nesta pesquisa, o evento discursivo é abordado enquanto texto, enquanto prática discursiva e enquanto prática social (FAIRCLOUGH, 2001, p. 22). Nesse caso, "discurso" é o produto do processo de produção textual, e "texto" é uma dimensão do discurso (FAIRCLOUGH, 2001, p. 21). No processo de recontextualização da popularização da ciência há um entrecruzamento entre os discursos da mídia e da ciência (e também da educação) com o objetivo de informar pedagogicamente um público de um contexto de cultura não especialista "sobre certos princípios e conceitos da ciência e da pesquisa" (MOTTA-ROTH; SCHERER, 2012, p. 640). Esse entrecruzamento discursivo é evidência de intertextualidade, ou de um "fluxo constante entre gêneros e discursos de diferentes esferas de atividade humana que integram um mesmo sistema que (re)cria e mantém a ciência" (MOTTA-ROTH; SCHERER, 2012, p. 640-641). Por consequência, a popularização da ciência é "uma ordem discursiva, um terreno de debates e práticas sociais" (MYERS, 2003, p. 65 apud GERHARDT, 2009, p. 63).

As ordens do discurso, na proposta de Fairclough (2003, p. 24-25), são a organização social e o controle da variação linguística, e seus elementos (gêneros, estilos e discursos) não correspondem a categorias puramente linguísticas, mas àquelas que estão na divisão entre linguagem e não linguagem, entre discursivo e não discursivo. O termo discurso é usado em um senso geral para linguagem (verbal e não verbal) como um elemento da vida social relacionado dialeticamente a outros elementos, e também usado mais especificamente; gênero é um modo de ação em seu aspecto discursivo (FAIRCLOUGH, 2003, p. 216); e estilos são modos de ser ou representar identidades em seus aspectos linguísticos e semióticos (FAIRCLOUGH, 2003, p. 41). (TAMANINI-ADAMES; LOVATO, 2011, p. 209-210).

A ACD define-se por uma heterogeneidade de abordagens em que a interdisciplinaridade é característica fundamental (RESENDE, 2009a, p. 11). O termo foucaultiano "ordens do discurso" é compreendido por Fairclough (2003, p. 220) como configurações particulares de gêneros (relacionados a significados textuais acionais e à metafunção textual), discursos (relacionados a significados textuais representacionais e à metafunção ideacional) e estilos (relacionados a significados textuais identificacionais e à metafunção interpessoal). Gêneros, discursos e estilos constituem o aspecto discursivo de uma rede de práticas sociais e têm relativa estabilidade. Ao propor três significados textuais existentes dialeticamente a partir das três metafunções hallidayanas, sendo o evento discursivo abordado enquanto texto e a linguagem vista como multifuncional, Fairclough (2003, p. 28) baseia-se em Bakhtin e Michel Foucault. Para Bakhtin (1997, p. 312), as estruturas composicional e temática preparam a entonação expressiva do gênero discursivo; e Foucault (1994, p. 318) preconiza três tipos de relações humanas: de ação sobre os outros, de controle sobre as coisas e de interação com os outros.

A interação envolve o letramento. Indivíduos com habilidades para participar com competência em práticas de escrita e leitura mantêm com o mundo "formas de interação, atitudes, competências discursivas e cognitivas" que lhes proporcionam um diferenciado "estado ou condição de inserção em uma sociedade letrada" (SOARES, 2002, p. 145). E, como entendo que um letramento é sempre um "letramento em algum gênero", "deve ser definido com respeito aos sistemas sígnicos empregados, às tecnologias materiais usadas e 
aos contextos sociais de produção, circulação e uso de um gênero" (LEMKE, 2010, p. 457). Conforme Bakhtin (1997, p. 279), cada esfera de utilização da língua vai elaborar seus gêneros do discurso que, "de uma forma imediata, sensível e ágil, refletem a menor mudança na vida social" (BAKHTIN, 1997, p. 285). Mas, na atual era digital, mesmo dominando perfeitamente a língua, podemos nos sentir desamparados em certas esferas da comunicação (como na esfera midiática digital) por não dominarmos, "na prática, as formas do gênero de uma dada esfera" (BAKHTIN, 1997, p. 303) (como as formas do gênero notícia on-line).

$\mathrm{Na}$ esfera midiática jornalística, a notícia pode ser definida como o "relato de uma série de fatos a partir do mais importante ou interessante", em uma ordem decrescente de importância, buscando expor um acontecimento de forma exata e precisa (LAGE, 2005, p. 16 apud LOVATO, 2010b, p. 3). Quanto ao conteúdo ser on-line, isso não afeta todas as suas etapas de criação e apresentação, que são orientadas pela aplicação dos princípios e processos jornalísticos básicos (WARD, 2007, p. 6). Porém, o meio on-line é um meio de comunicação diferenciado porque é controlado pelo usuário e multifacetado, é um meio de comunicação onde todos os seus elementos devem apoiar a oferta de conteúdo (WARD, 2007, p. 6). "A publicação on-line pode abrir novas possibilidades na disseminação de informações e estabelecer um relacionamento mais dinâmico com o leitor" (WARD, 2007, p. 21). Cores, imagens, layout, links, etc., são recursos constitutivos da "enunciação digital" (XAVIER, 2009). Essa construção composicional presente na webnotícia ou notícia on-line engloba diversos modos semióticos e "multiletramentos".

A concepção de "multiletramentos focaliza dois desenvolvimentos-chave nas sociedades contemporâneas: multimodalidade e hibridismo cultural, sendo o conceito de ordens do discurso útil aos dois. (FAIRCLOUGH, 2006, p. 171-173). A multimodalidade está envolvida em toda construção de significado (COPE; KALANTZIS, 2000, p. 29). Os signos têm realidade material e, como tal, carregam significados definidos por mais de um código ou mídia: "toda semiótica é semiótica multimídia e todo letramento é multimidiático" (LEMKE, 2010, p. 456). A $W e b^{3}$ é baseada no consumo não linear, é uma rede, em vez de uma linha, cujo consumo é controlado pelo público (WARD, 2007, p. 24-25). Além disso, a multimodalidade imprime particularidades ao texto da $W e b$, e "o que parece ser o mesmo texto ou gênero multimidiático não é funcionalmente o mesmo quando no papel ou na tela" (LEMKE, 2010, p. 457). Quanto ao hibridismo, mistura de duas linguagens dentro dos limites de um único enunciado (BAKHTIN, 1981, p. 358 apud PAGANO; MAGALHAES, 2005, p. 25), pode ser analisado sob uma perspectiva discursiva em termos de fronteiras/limites e fluxos instáveis entre diferentes contextos de cultura ou ordens do discurso. O discurso de popularização da ciência on-line é um exemplo de hibridismo cultural, na medida em que mobiliza os contextos científico e midiático.

Em relação ao gênero notícia de popularização da ciência, constitui-se em um texto publicado pela mídia jornalística, geralmente relatando e comentando "resultados de pesquisas científicas recentes de modo a explicar seu conteúdo e sua relevância para a audiência-alvo da publicação", e geralmente contendo três partes: uma síntese, um detalhamento e uma conclusão avaliativa (MOTTA-ROTH; LOVATO, 2011, p. 257-256). Mas, no caso da notícia on-line, sua estrutura retórica ou construção composicional está em

\footnotetext{
${ }^{3}$ Em relação à terminologia, um "processo digital" separa informações numa sequência de dígitos, transporta-as a um destino, e finalmente agrupa-as na forma original (como textos, imagens, sons ou vídeos); "on-line" descreve acesso, recuperação ou disseminação de informação digital; "Internet" é o que permite aos computadores comunicarem-se e não se confunde com "Web", interface possibilitadora da troca de dados através da Internet; e, finalmente, "World Wide Web" é um dos comunicadores da Internet (como o e-mail) (WARD, 2007, p. 8-10).
} 
forma de "pirâmide deitada", com aprofundamento em níveis, a fim de oferecer links para a expansão (CANAVILHAS, 2006, p. 14). Esses níveis são em número de quatro, segundo Canavilhas (2006): o lead ou "quando, quem e onde"; a explicação; a contextualização; e o nível de exploração, que liga a notícia a arquivos externos. Em muitas notícias de popularização da ciência on-line, o nível de exploração promove a interface entre as esferas midiática e científica, permitindo ao leitor-internauta o acesso a maiores informações em relação ao tema abordado quando, por meio de um hiperlink, ele acessa o artigo científico recontextualizado.

A popularização da ciência, portanto, é um processo de recontextualização e reformulação do discurso científico, muitas vezes para os meios de comunicação de massa, mas sempre visando a uma audiência não especializada (CALSAMIGLIA; LOPÉS FERRERO, 2003, p. 68). Desse modo, o gênero discursivo notícia de popularização da ciência on-line, o qual me proponho a analisar aqui através de suas imagens, tem no estudo da interdiscursividade um recurso relevante para seu entendimento. Conforme Fairclough (2001, p. 285), esse tipo de realização da intertextualidade constitui-se como uma espécie de "área cinzenta" entre o evento discursivo abordado enquanto prática discursiva e o evento discursivo abordado enquanto texto (no caso, texto não verbal), como discuto na sequência.

\section{1 Recontextualização do discurso científico e interdiscursividade}

Segundo Fairclough (2003, p. 51), intertextualidade é uma questão de recontextualização, um movimento de um contexto para outro, onde se forma outro contexto, apontando para o modo como textos podem transformar textos anteriores e reestruturar convenções existentes (FAIRCLOUGH, 2001, p. 135). Enquanto uma análise linguística é descritiva por natureza, uma análise intertextual é mais interpretativa, sendo ambas complementares (FAIRCLOUGH, 1995, p. 61). A abordagem sistêmica tem papel crucial nesta análise linguística/semiótico-social crítica, "em função do seu pressuposto da linguagem enquanto escolha ou seleção de opções dos sistemas que constituem os potenciais de significado (PAGANO; MAGALHÃES, 2005, p. 27). A análise intertextual é inspirada nesse pressuposto, mas vê o texto como escolha num nível de análise que envolve "uma seleção de opções dentro do que se pode chamar de potencial intertextual de uma ordem de discurso abrangendo a inclusão e a exclusão" (FAIRCLOUGH, 2000, p. 208 apud PAGANO; MAGALHÃES, 2005, p. 27-28).

Linguistic features of texts provide evidence which can be used in intertextual analysis, and intertextual analysis is a particular sort of interpretation of that evidence - an interpretation which locates the text in relation to social repertoires of discourse practices, i.e. orders of discourse. (FAIRCLOUGH, 1995, p. 61).

As concepções de texto e de prática discursiva desenvolvidas na ACD por Fairclough estão conectadas ao conceito de intertextualidade, termo cunhado por Kristeva a partir da noção bakhtiniana de dialogismo. Kristeva (1974, p. 59 apud VASQUES, 2007, p. 22), fundamentando-se no princípio dialógico da linguagem preconizado por Bakhtin, define intertextualidade como uma "transposição de um (ou vários) sistema(s) de signos noutro". No entanto, há dois conceitos para o termo "dialogismo", o qual refere-se às "relações de sentido que se estabelecem entre dois enunciados" (FIORIN, 2006, p. 19). 
No primeiro conceito, chamado de constitutivo - que "não se mostra no fio do discurso" (FIORIN, 2006, p. 32) -, "dialogismo é o modo de funcionamento da linguagem", pois todo enunciado constitui-se a partir de outro enunciado e tem pelo menos duas vozes, diz Fiorin (2006, p. 24). No segundo, chamado de composicional - que se mostra -, há a "incorporação pelo enunciador da(s) voz(es) do outro no enunciado" (FIORIN, 2006, p. 32). (PIRES; TAMANINI-ADAMES, 2010, p. 68).

Da mesma forma, há duas maneiras de realização da intertextualidade em um texto (FAIRCLOUGH, 2001, p. 136 com base em AUTHIER-RÉVUZ, 1982; MAINGUENAU, 1987). A manifestação gráfica da intertextualidade está relacionada à recorrência explícita a outros textos e é chamada de "intertextualidade manifesta" (doravante intertextualidade) (FAIRCLOUGH, 2001, p. 136). Já a "intertextualidade constitutiva" (doravante interdiscursividade), minha categoria analítica, tem seu foco em convenções (gêneros, discursos, estilos, tipos de atividade) que estão estruturadas juntas e constituem uma ordem do discurso (FAIRCLOUGH, 2001, p. 136-137). "Embora a interdiscursividade envolva hibridizações, não só de discursos, mas de gêneros e estilos, frequentemente pela análise da interdiscursividade investigamos discursos articulados em textos e suas conexões com lutas hegemônicas mais amplas" (RAMALHO; RESENDE, 2011, p. 142). Na popularização da ciência, entretanto, em vez de uma separação entre discursos, o processo de recontextualização pode dar visibilidade ao fluxo "entre gêneros que integram o mesmo sistema de criação, recriação e manutenção da ciência" (MOTTA-ROTH, 2010, p. 154-155). $\mathrm{Na}$ interdiscursividade, a atenção volta-se para os discursos e as maneiras como esses são articulados ou não nos textos, assim como para as maneiras como são articulados com outros discursos (RAMALHO; RESENDE, 2011, p. 142), como a articulação entre o discurso científico e o discurso de sua popularização.

Assim sendo, os conceitos de intertextualidade e interdiscursividade desenvolvidos por Bakhtin (nomeados assim por Kristeva) e Fairclough (a partir da Análise do Discurso de linha francesa) referem-se aos vários textos ou discursos que são atualizados e reproduzidos em outros, ou seja, recontextualizados. Essa "indissolubilidade na relação texto-contexto" pontua não só uma análise crítica (VIAN JR., 2009, p. 105), mas também uma análise sistêmico-funcional. Há "alguns possíveis diálogos, embora de perspectivas espaciais, sociais e teóricas diferentes, entre Bakhtin e Halliday" (VIAN JR., 2009, p. 106), visto que, na GSF, o significado é produto das interrelações entre as partes do texto e do contexto (MARTIN, 1992, p. 497). Na LSF desenvolvida por Halliday, portanto, tanto a interação verbal permanente entre os participantes do diálogo quanto a intertextualidade e a interdiscursividade ou a relação dialética interdependente entre discurso e contexto correlacionam-se de maneira relevante com o dialogismo (VIAN JR., 2009, p. 106).

Intertextualidade e interdiscursividade, à vista disso, têm como característica serem seletivas em relação ao que será incluído ou excluído dos eventos e dos discursos representados (FAIRCLOUGH, 2003, p. 55). E, como os meios de comunicação (caso do jornalismo científico on-line) são antes de tudo um negócio cujo produto a vender é a informação, dependem do tipo e da forma em que essa informação está apresentada (IVANISSEVICH, 2005, p. 14). Na mídia, em relação aos textos não verbais, os quais proponho-me a analisar interdiscursivamente em uma perspectiva multimodal, as imagens comumente são usadas para capturar a essência da informação a ser comunicada (LOVATO, 2010a, p. 115). 
Textos, portanto, refletem representações de mundo, relações sociais, identidades sociais e valores culturais. A análise textual é a análise de como textos atuam no estabelecimento de representações, relações, identidades e valores - no julgamento de valores (FAIRCLOUGH, 2001). A análise interacional engloba dois momentos: a análise interdiscursiva e a análise linguística (CHOULIARAKI \& FAIRCLOUGH, 1999), lembrando que essa última é feita dentro de uma perspectiva multimodal [...]. (TILIO, 2010, p. 97)

Na recontextualização do discurso científico, os textos normalmente trazem no visual "elementos que possibilitam ao leitor se identificar com o que está sendo retratado" (MILLER, 1998, p. 40 apud LOVATO, 2010a, p. 125). Analisando notícias da revista Ciência Hoje On-line baseada na GDV, Lovato (2010a, p. 130) conclui que a função dessas imagens de popularização da ciência on-line é a de índice, indicando por meio de uma fotografia um dos tópicos da pesquisa popularizada, comumente o objeto de análise e/ou a fonte de dados, e reproduzindo "os interesses do grupo social no qual são produzidas e para o qual se dirigem". No caso da popularização da ciência, as imagens buscam materializar situações, instituindo referentes para os fenômenos científicos abordados no texto verbal (PEREIRA, 2003, p. 146147 apud LOVATO, 2010a, p. 115). Porém, ainda que só sobreviva em ambiente multimodal, a cor, sobre a qual discorro a seguir, não é analisada nas imagens como modo semiótico nesses estudos.

\section{Gramática do Design Visual e Semiótica Social da Cor}

Ao proporem uma GDV inserida na abordagem da Semiótica Social, Kress e Van Leeuwen foram pioneiros na ideia de aplicar a noção de metafunção da GSF na análise de imagens, vistas como estruturas sintáticas passíveis de um exame tal qual na linguagem verbal (KRESS; VAN LEEUWEN, 2006, p. 1). A GDV descreve o modo pelo qual elementos representados nas imagens se combinam em arranjos visuais, assim como a GSF descreve como as palavras se combinam em orações, sentenças e textos. A abordagem sistêmico-funcional pode ser adequada para a análise sintática de qualquer sistema semiótico, pois o que interessa é "o estudo da função, e não da forma" (SANTOS; SOUZA, 2008, p. 4). Mas na ACD "não basta desenvolver uma abordagem multimetodológica e multidimensional, é preciso estar consciente da funcionalidade dessa abordagem na exploração das questões de pesquisa" (RESENDE, 2009a, p. 65).

A teoria semiótica funcional das imagens, "ao utilizar uma organização metafuncional também realizará seus significados através das mesmas funções" (UNSWORTH, 2001, p. 72 apud NOVELINO, 2006, p. 381). A metafunção composicional ou textual refere-se a significados relacionados à distribuição do valor da informação ou ênfase relativa entre os elementos da imagem; a metafunção representacional ou ideacional refere-se a estruturas que constroem visualmente a natureza dos eventos, objetos e participantes envolvidos e circunstâncias em que ocorrem; e a metafunção interpessoal referese a recursos visuais que constroem a natureza das relações de quem vê e o que é visto (UNSWORTH, 2001, p. 72 apud NOVELINO, 2006, p. 381).

Tratando-se de cores, elas igualmente significam (KRESS; VAN LEEUWEN, 2002, p. 343), e seus signos são "motivados" (VAN LEEUWEN, 2005, p. 62). Uma cor expressa diferentes significados, e um significado pode ser expresso por diferentes cores (VAN LEEUWEN, 2011, p. 15). Analisar cores por intermédio da teoria metafuncional significa olhar para a interação social, para a expressão de sentimentos e comunicação de ideias, (VAN 
LEEUWEN, 2011, p. 1). Cores, portanto, exercem as funções textual, ideacional e interpessoal, mas em certos tempos uma função se sobrepõe às outras (VAN LEEUWEN, 2011, p. 97). A função textual é observada quando se usa a repetição de cores para dar um valor simbólico a um produto, quando ajuda na coerência ou na coesão textual pela sua coordenação (KRESS; VAN LEEUWEN, 2002, p. 349). Em relação à função ideacional, a cor pode ser usada para denotar pessoas, lugares e coisas, bem como classes deles, e ideias (KRESS; VAN LEEUWEN, 2002, p. 347). Além disso, quando a cor é ideacional, expressando ou significando uma qualidade, sempre exerce a função interpessoal fazendo essa qualidade manifestar-se nos observadores, agindo sobre eles (KRESS; VAN LEEUWEN, 2002, p. 349). Quanto à função interpessoal ou identificacional, podemos comparar a linguagem, que permite a realização de atos de fala, com as cores, que permitem a percepção de "atos de cores", com as cores sendo usadas tanto para impressionar ou intimidar quanto para reduzir ou aumentar os níveis de estresse (KRESS; VAN LEEUWEN, 2002, p. 348-349). Porém, os significados das cores são mais múltiplos, e com funções cruzadas, do que os expressos pelos sistemas linguísticos, requerendo uma abordagem diferente, (VAN LEEUWEN, 2011, p. 8). Embora a cor cumpra as três metafunções simultaneamente, não é um modo semiótico relativamente independente, como a linguagem e a imagem (KRESS; VAN LEEUWEN, 2002, p. 350). A cor pode se combinar livremente com muitos modos, mas só sobrevive em um ambiente multimodal (KRESS; VAN LEEUWEN, 2002, p. 351).

Kress e Van Leeuwen (2002, p. 352) destacam diferentes abordagens para as cores ao longo da história, entre elas, a psicológica e interpessoal, baseada na impressão à cor. A psicologia da cor contemporânea entende o significado da cor como instintivo, acalmando ou estimulando (VAN LEEUWEN, 2011, p. 55). Mas, embora as cores possam ser padronizadas, seus significados não o são, podendo ter diferentes conotações em diferentes tempos e culturas (KRESS; VAN LEEUWEN, 2002, p. 353-344). Parte do problema pode não ter a ver com a cor, mas com as noções de significado ou de gramática (KRESS; VAN LEEUWEN, 2002, p. 344).

No presente artigo, uma "gramática" é entendida como descrevendo as regularidades do que as pessoas fazem, existindo convenção e consenso (KRESS; VAN LEEUWEN, 2002, p. 344). No caso de uma "gramática da cor", Kress e Van Leeuwen (2002, p. 345) advertem que não há um grupo grande ou poderoso suficientemente que sustente um entendimento compartilhado dos significados da cor por entre toda a sociedade. Porém, a cor é um recurso semiótico como qualquer outro: regular, com sinais motivados em sua constituição pelos interesses dos produtores de sentido, e não totalmente arbitrária ou anárquica (KRESS; VAN LEEUWEN, 2002, p. 345). Nessa abordagem multimodal e semiótico-social, Kress e Van Leeuwen (2002, p. 345-346) valem-se do termo "gramáticas do recurso", entendendo que se um recurso é suficientemente desenvolvido para ser um signo será chamado de modo. O que torna um modo um modo é sua disponibilidade como um recurso para produzir um signo dentro de um grupo sociocultural; e o que faz uma gramática uma gramática é ter características que podem ser violadas, pois podemos reconhecer um agramatismo (KRESS; VAN LEEUWEN, 2002, p. 346). Então, a teoria moderna da cor a concebe como um modo, como um sistema gerativo-abstrato de tonalidades, modificado por valor e saturação (VAN LEEUWEN, 2011, p. 34).

Olhar a cor como um recurso semiótico não significa olhar somente para sua materialidade e tecnologia, mas para o que fazemos com ela (VAN LEEUWEN, 2011, p. 2). Estudar a Semiótica Social da Cor significa estudar os recursos e as práticas semióticas (VAN LEEUWEN, 2011, p. 4). Significantes (e, portanto, também cores) carregam um conjunto de possibilidades de significados que podem ser selecionados pelos produtores/intérpretes, 
conforme suas necessidades comunicativas em determinado contexto (KRESS; VAN LEEUWEN, 2002, p. 355). Uma das possibilidades de significação de cor é por meio de traços distintivos que indicam uma qualidade visual sistematizada como valores em escalas (KRESS; VAN LEEUWEN, 2002, p. 354-355). São dez as escalas propostas: valor, saturação, pureza, transparência, luminosidade, luminescência, brilho, temperatura/tonalidade, modulação e diferenciação (VAN LEEUWEN, 2011, p. 60-65). Nessa abordagem paramétrica para a análise da cor (VAN LEEUWEN, 2011, p. 57) ou abordagem de traços distintivos para a Semiótica da Cor (KRESS; VAN LEEUWEN, 2002, p. 355), os recursos são potenciais de significação e qualquer instância de uma cor pode ser analisada como uma combinação de valores específicos em cada uma das escalas (KRESS; VAN LEEUWEN, 2002, p. 355).

A escala de "valor" é a escala cinza, do máximo de luz (branco) até ao máximo de escuridão (preto) (VAN LEEUWEN, 2011, p. 60). A escala de "saturação" vai das manifestações mais puras da cor (tendendo para preto) às mais pastéis (tendendo para branco) (KRESS; VAN LEEUWEN, 2002, p. 356; VAN LEEUWEN, 2011, p. 61). A escala de "pureza" vai dos puros vermelhos, azuis ou amarelos ao hibridismo máximo (VAN LEEUWEN, 2011, p. 61). A escala de "transparência" vai do mais transparente (luz passando através da cor) ao translúcido (luz parcialmente bloqueada) e ao opaco (VAN LEEUWEN, 2011, p. 62). A escala de "luminosidade/fosforescência" é a capacidade de fosforescer: cores mais claras e saturadas são mais luminosas (VAN LEEUWEN, 2011, p. 62). A escala de "luminescência" refere-se a uma cor emitida diretamente por uma fonte de luz, diferentemente da escala de "brilho", que resulta da luz refletida por superfícies coloridas (como o dourado) (VAN LEEUWEN, 2011, p. 63). A escala de "temperatura/tonalidade" vai do mais baixo/frio (extremidade azul) ao mais alto/quente (extremidade vermelha) (KRESS; VAN LEEUWEN, 2002, p. 357; VAN LEEUWEN, 2011, p. 63). A escala de "modulação" vai da cor mais modulada/texturizada à cor mais lisa, estando intimamente relacionada à modalidade: cor modulada é específica e mostra uma verdade naturalista; cor lisa é genérica e expressa uma verdade abstrata (KRESS; VAN LEEUWEN, 2002, p. 356-357; VAN LEEUWEN, 2011, p. 64). Por fim, a escala de "diferenciação" vai do monocromático à máxima utilização da paleta de cores (KRESS; VAN LEEUWEN, 2002, p. 357; VAN LEEUWEN, 2011, p. 65).

Para Kress e Van Leeuwen (2002, p. 366), todas as cores são cores de um esquema de cores, cores em sistemas de cor que podem ser definidos por intermédio de usos específicos destes traços distintivos. Tais esquemas de cores fazem referência à gramática (regularidades) e ao social (ideologia) (KRESS; VAN LEEUWEN, 2002, p. 366). Portanto, qualquer instância de uma cor pode ser analisada como potenciais metafóricos em contextos específicos (VAN LEEUWEEN, 2011, p. 58), como discuto no próximo subitem.

\subsection{Significados identificacionais de cor e interdiscursividade}

A abordagem de traços distintivos para a Semiótica Social da Cor (KRESS; VAN LEEUWEN, 2002, p. 355) é uma abordagem paramétrica (VAN LEEUWEN, 2011) que propõe a análise das cores como potenciais de significado (KRESS; VAN LEEUWEN, 2002, p. 355). Esses potenciais são factíveis metafóricos em contextos específicos (VAN LEEUWEEN, 2011, p. 58). E "metáforas moldam significados identificacionais em textos, pois, ao selecioná-las num universo de outras possibilidades, o/a locutor/a compreende sua realidade e a identifica de maneira particular" (RAMALHO; RESENDE, 2011, p. 146). A competência metafórica, portanto, tem um papel importante em todas as áreas da competência comunicativa (LITTLEMORE; LOW, 2006, p. 268 apud LOURENÇO, 2010, p. 15). 
A essência da metáfora "é compreender uma coisa em termos de outra" (LAKOFF; JOHNSON, 2002, p. 49-50 apud RESENDE, 2009b, p. 138). Referindo-se ao texto verbal, Lakoff e Johnson desenvolveram a teoria da metáfora conceitual, entendida como um fenômeno mental, cognitivo e abstrato que serve para conceitualizar um domínio da experiência, como uma abstração, em termos de outro (SARDINHA, 2007, p. 17 apud LOURENÇO, 2010, p. 24). Baseadas em Lakoff e Johnson (2002), Ramalho e Resende (2011, p. 146) observam que "nosso sistema conceitual é metafórico por natureza", já que sempre compreendemos aspectos do mundo estabelecendo correlações.

No presente artigo, no entanto, valho-me do conceito de metáfora lexicogramatical proposto na LSF por Halliday (1985, p. 321 apud LOURENÇO, 2010, p. 29) a partir dos conceitos de metáfora lexical e metáfora gramatical. Mas relaciono o conceito ao texto não verbal. O léxico pode ser entendido como o conjunto de signos linguísticos pelos quais nos expressamos, nos comunicamos e assimilamos e produzimos conhecimento. A Semiótica, ciência dos signos e da semiose, estuda fenômenos culturais como sistemas sígnicos ou de significação. Já a Semiótica Social estuda a significação em condições culturais determinadas, mudando o foco do signo para o uso de recursos semióticos em contextos específicos, segundo Van Leeuwen (2005). Assim, estudar a Semiótica Social da Cor implica estudar os recursos e as práticas semióticas, com as cores carregando um conjunto de possibilidades de significados (VAN LEEUWEEN, 2011, p. 4). Nessa "gramática do recurso", a cor é vista como um modo semiótico, ou seja, como um recurso suficientemente desenvolvido para ser um signo (KRESS; VAN LEEUWEN, 2002, p. 345-346).

A metáfora lexical é entendida como uma construção não literal ou conotativa de expressar significados (LOURENÇO, 2010, p. 14), havendo transferências verbais de vários tipos (HALLIDAY, 1985, p. 319 apud LOURENÇO, 2010, p. 32). Porém, a seleção lexical é apenas um aspecto da seleção gramatical ou do fraseado (HALLIDAY, 1985, p. 321 apud LOURENÇO, 2010, p. 29-30). "A metáfora lexical e a metáfora gramatical não são dois fenômenos diferentes; eles são aspectos da mesma estratégia metafórica geral pela qual expandimos nossos recursos semânticos para construir a experiência" (LOURENÇO, 2010, p. 34 com base em HALLIDAY, 1985). O foco da metáfora, desse modo, situa-se na semântica (VILELA, 1996, p. 319). Conforme Paul Ricoeur (1975, p. 76), há uma discussão acerca da semântica do discurso não poder ser reduzível à semiótica de entidades lexicais, todavia, essas teorias advêm mais de lógicos e epistemólogos do que de linguistas. Vistas como um modo semiótico, pode-se dizer o mesmo em relação às cores, analisadas neste trabalho como potenciais metafóricos em contextos específicos (VAN LEEUWEEN, 2011, p. 58). Se por um lado temos milhares de tonalidades reconhecíveis pela nossa visão (que assim recairá sobre o processo da percepção), "por outro temos muito menos cores no processo da cognição, pois aqui estaremos condicionados à sua codificação semântica" (PERNÃO, 2005-2006, p. 7).

No esforço de explicação da metáfora, chega-se à conclusão de que a teoria da metáfora e a teoria do texto têm uma base comum: o discurso, é que não há metáfora sem contexto, mesmo que a instanciação da transferência (= foco) incida na palavra, e ainda que este foco exija um enquadramento (= frame) frásico. (VILELA, 1996, p. 323 com base em RICOEUR, 1975).

De qualquer modo, toda metáfora é uma escolha linguística consciente que esconde processos sociais subjacentes (CHARTERIS-BLACK, 2004 apud VIEIRA, 2008, p. vii) e requer um exercício de abstração. No discurso verbal, o princípio da abstração proposto por Fairclough (2003, p. 139 com base em BERNSTEIN, 1990) é uma maneira de se verificar a interdiscursividade, ou o modo como valores, crenças e modos habituais de um discurso são 
atualizados em outro (FAIRCLOUGH, 1995, p. 95). Sob o ponto de vista da representação de eventos discursivos como recontextualização, um processo em que um evento discursivo está incorporado no contexto de outro evento discursivo, recontextualizado, Fairclough (2003, p. 139 com base em BERNSTEIN, 1990) propõe princípios específicos que permitem a verificação de marcas de interdiscursividade. Dentre esses princípios, que diferem quanto aos modos pelos quais um tipo particular de evento discursivo está representado em diferentes campos, redes de práticas sociais e gêneros, está o da abstração, ou o grau de abstração de eventos concretos. Pelo fato de eu analisar cores em imagens como potenciais metafóricos (VAN LEEUWEEN, 2011, p. 58) e da linguagem científica favorecer abstrações (FAIRCLOUGH, 2001, p. 223), expando essa discussão acerca da abstração como marca de interdiscursividade ao discurso não verbal. Campos sociais particulares, redes de práticas sociais particulares, e gêneros (como o gênero discursivo notícia de popularização da ciência on-line) têm a eles associados princípios de recontextualização conforme incorporam e atualizam eventos discursivos prévios (FAIRCLOUGH, 2003, p. 139 com base em BERNSTEIN, 1990).

No evento discursivo abordado enquanto texto, a interdiscursividade está "ligada a maneiras particulares de representar aspectos do mundo", sendo, "em princípio, uma categoria representacional" (RAMALHO; RESENDE, 2011, p. 142) ou ideacional. Todavia, mesmo que cores expressem ideias (KRESS; VAN LEEUWEN, 2002, p. 348) e visualizações científicas sejam principalmente ideacionais, com as cores destinadas a distinguir diferentes partes e sugerir aspectos do significado (KRESS; VAN LEEUWEN, 2002, p. 350), as cores sempre enviam mensagens aos leitores e apresentam valores em situações sociais específicas (KRESS; VAN LEEUWEN, 2002, p. 347). Adicionalmente, abstrações ou metáforas envolvem essencialmente uma reconstrução de experiência, mas que implicam em consequências textuais e interpessoais (HEYVAERT, 2003, p. 86) ou identificacionais. Por conseguinte, no presente artigo, destaco a ordem discursiva de estilo e a função interpessoal ou os significados identificacionais, em relevo na mídia, e me refiro a metáforas gramaticais interpessoais, que advêm de relações interpessoais (TAVERNIERS, 2004, p. 5). Segundo Halliday e Matthiessen (2004), metáforas interpessoais podem ser de modo ou de modalidade, essa última o meu interesse. A modalidade expressa a atitude do falante em relação à probabilidade ou necessidade da proposição, e nos textos verbais é realizada na forma congruente por verbos modais (THOMPSON, 2004, p. 232 apud LOURENÇO, 2010, p. 32). Nos textos não verbais, a modalidade refere-se aos recursos semióticos que expressam "quão verdadeira ou real uma dada representação pode ser" (VAN LEEUWEN, 2011, p. 22).

Neste estudo, analiso o significado da cor por meio de valores em escalas, recursos semióticos que sistematizam traços distintivos indicadores de qualidade visual, (KRESS; VAN LEEUWEN, 2002, p. 354-355). Na função interpessoal, relacionada a significados identificacionais e estilo, esses valores em escalas, que são potenciais de significado ou metafóricos, estão envolvidos em julgamentos de modalidade visual dependentes do contexto, postula Van Leeuwen (2005). As imagens podem apresentar modalidade naturalística, sensorial, tecnológica e abstrata (VAN LEEUWEN, 2005, p. 167-171). A modalidade abstrata é característica de imagens da ciência (VAN LEEUWEN, 2005, p. 168).

A seguir, exponho a metodologia empregada nesta que se configura em uma análise linguística/semiótico-social interdiscursiva de perspectiva multimodal.

\section{Metodologia}


Meu corpus é composto por oito imagens veiculadas em um artigo científico disponibilizado no meio digital intitulado City living and urban upbringing affect neural social stress processing in humans (LEDERBOGEN et al., 2011) e oito imagens destacadas em oito notícias oriundas de oito diferentes sites que popularizam ciência on-line ao recontextualizar esse artigo.

As imagens do artigo científico recontextualizado estão expostas no Quadro 1.

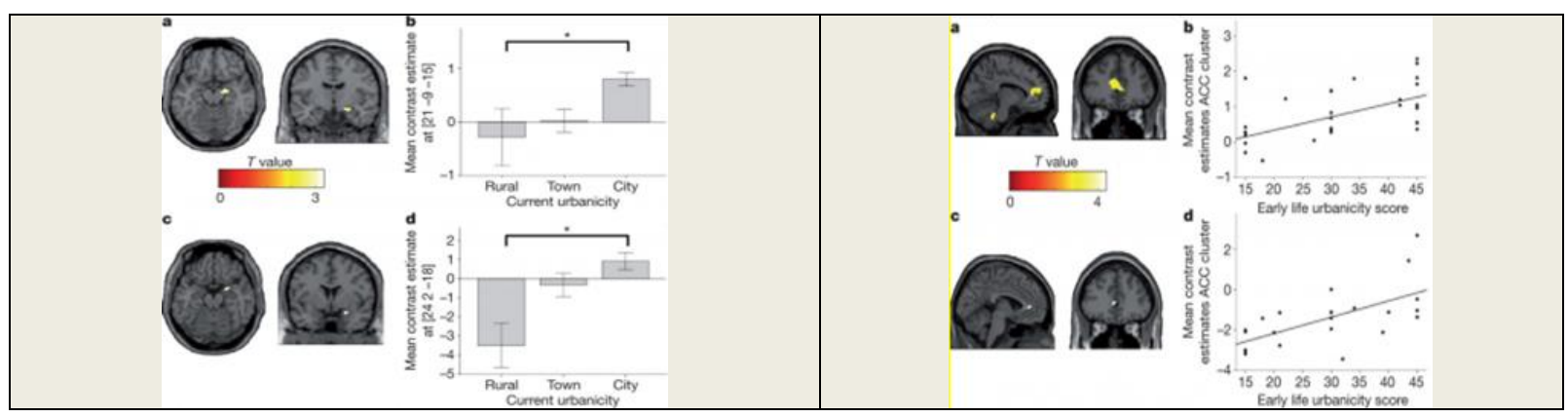

Quadro 1 - Imagens do artigo científico.

Os sites com as notícias de popularização da ciência e respectivas imagens selecionadas são: $1^{\circ}$ Ciência Hoje On-line (Disponível em: <http://cienciahoje.uol.com.br/noticias/2011/06/insani-ci-dade>. Acesso em:13 jun. 2012.) Imagem $\quad 1 ; \quad 2^{\circ} \quad$ Scientific American (Disponível em: $<$ http://blogs.scientificamerican.com/scicurious-brain/2011/08/16/city-living-and-yourmental-health-is-city-living-driving-you-crazy/>. Acesso em: 13 jun. 2012.) - Imagem 2; $3^{\circ}$ Nature (Disponível em: <http://www.nature.com/news/2011/110622/full/474429a.html>. Acesso em: 13 jun. 2012.) - Imagem 3; 4 Science Daily (Disponível em: <http://www.sciencedaily.com/releases/2011/06/110622135216.htm>. Acesso em: 13 jun. 2012.) - Imagem 4; $5^{\circ}$ Wired Science (Disponível em: <http://www.wired.com/wiredscience/2011/06/city-brains/>. Acesso em: 13 jun. 2012.) Imagem 5; $6^{\circ}$ Per Square Mile (Disponível em: <http://persquaremile.com/2011/06/28/this-isyour-brain-in-the-city/>. Acesso em: 13 jun. 2012.) - Imagem 6; $7^{\circ}$ Research Digest (Disponível em: <http://bps-research-digest.blogspot.com.br/2011/06/living-or-growing-upin-city-is.html>. Acesso em: 13 jun. 2012.) - Imagem 7; e $8^{\circ}$ Big Think (Disponível em: <http://bigthink.com/ideas/39004>. Acesso em: 13 jun. 2012.) - Imagem 8.

$\mathrm{O}$ critério de seleção das imagens das notícias de popularização da ciência on-line, para fins de comparação com as imagens do artigo científico, foi que, mesmo que o site apresentasse mais de uma imagem na referida notícia, eu consideraria somente a primeira imagem, por entender ser a mais representativa da ideia contida no respectivo título. Os títulos não são analisados linguisticamente aqui, mas a necessidade de mencioná-los deve-se a situarem tematicamente os textos, o que favorece a identificação do contexto na minha proposta de análise interdiscursiva multimodal, pois as cores não são um modo semiótico relativamente independente por elas mesmas (KRESS; VAN LEEUWEN, 2002, p. 350).

As imagens analisadas e os respectivos títulos das notícias que as veiculam estão expostas no Quadro 2. 
CASA, Vol.11 n.2, dezembro de 2013

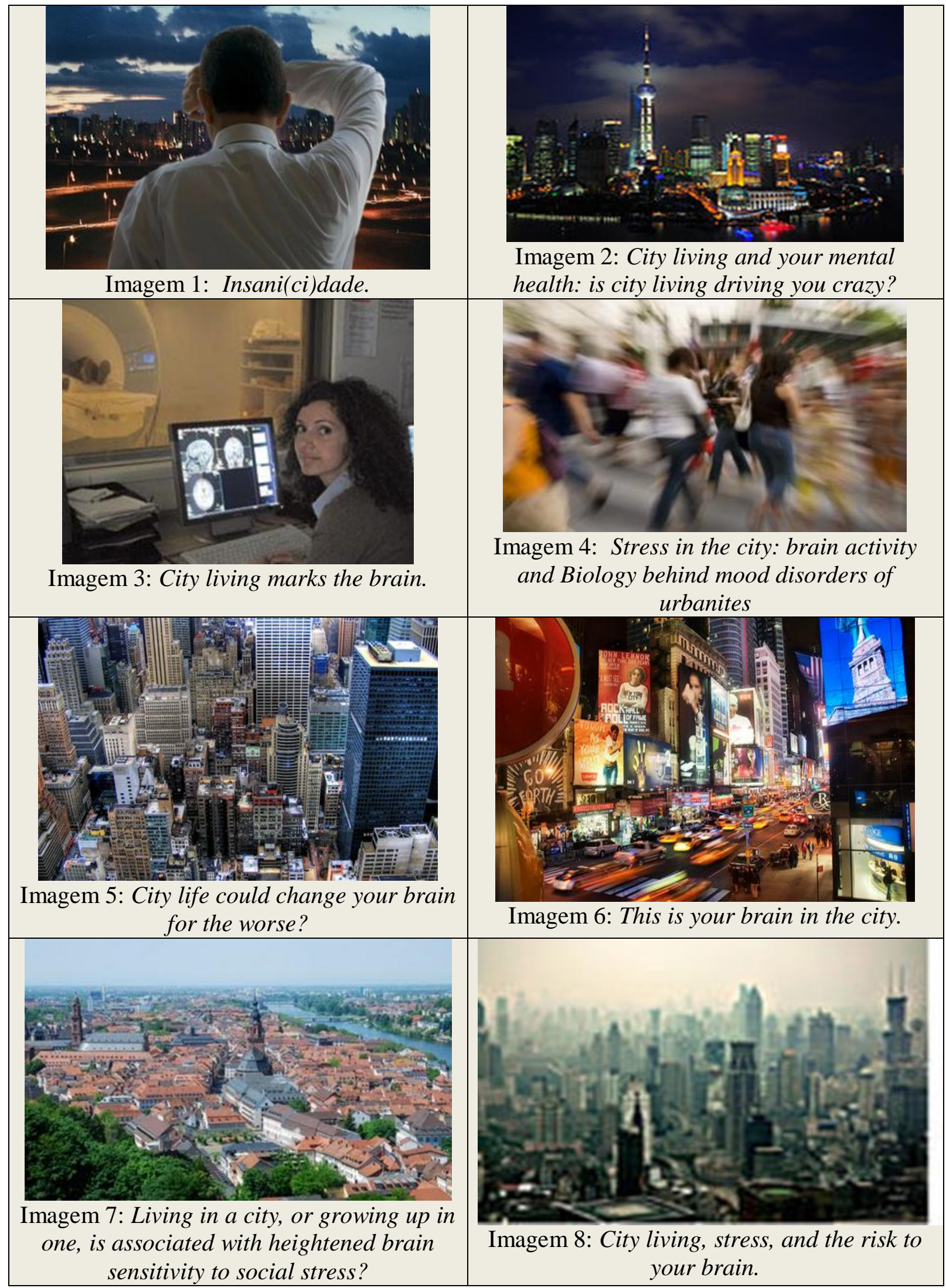

Quadro 2 - Imagens da popularização da ciência on-line e respectivos títulos das notícias onde aparecem.

Disponível em: http://seer.fclar.unesp.br/casa 
Dentro da abordagem de traços distintivos para a Semiótica da Cor proposta por Kress e Van Leeuwen (2002) e Van Leeuwen (2011), na qual a instância de uma cor pode ser analisada como uma combinação de valores específicos em escalas, os procedimentos de análise das imagens compreenderam a verificação das possibilidades de significação de cor por meio de traços distintivos através das escalas de valor, saturação, pureza, transparência, luminosidade/fosforescência, luminescência, brilho, temperatura/tonalidade, modulação, e diferenciação.

Também, considerando que esses recursos estão envolvidos em julgamentos de modalidade visual (VAN LEEUWEN, 2005), analiso a modalidade das imagens, evidenciando a função interpessoal/identificacional.

No presente artigo, esses procedimentos metodológicos estão vinculados à abordagem da ACD e ao estudo da interdiscursividade.

\section{Análise e discussão}

Quanto às escalas, todas as imagens do corpus são luminescentes, pois as cores são emitidas pela tela do computador, uma fonte de luz. As oito imagens veiculadas no artigo científico são frias; não apresentam transparência nem brilho; valor, modulação e diferenciação são baixos; saturação e pureza são altas; e não há fosforescência, à exceção das duas imagens "a", onde é leve (Quadro 1). Em todas essas imagens, a modalidade é abstrata. Isso apoia o fato de suas cores serem lisas, apresentando baixa modulação, característica da expressão de verdades abstratas (VAN LEEUWEN, 2011, p. 64). A modalidade abstrata é comum em visualizações científicas (VAN LEEUWEN, 2005, p. 168). Discursos são formas de representar o mundo em diferentes níveis de abstração (FAIRCLOUGH, 2003, p. 133), e estudos anteriores de textos verbais demonstram que um discurso altamente abstrato ou metafórico tende também a diferenciar o discurso do especialista do não especialista, de acordo com Halliday e Matthiessen (2004). A abstração, verificada pela presença de metáforas nos textos verbais, está associada a discursos de prestígio, poder e autoridade, como o discurso da ciência (HALLIDAY; MATTHIESSEN, 2004, p. 640), ao contrário do discurso não especialista da popularização da ciência. Nas notícias de popularização da ciência, por outro lado, todas as imagens analisadas referem-se à modalidade naturalística, mas em graus diversos, com a maioria combinando-se a outra modalidade (Quadro 2). Isso apoia o fato de suas cores serem moduladas, característica da expressão de verdades naturalistas, não abstratas (VAN LEEUWEN, 2011, p. 64). "Imagens de cunho naturalístico são oferecidas ao leitor como itens de informação e contemplação" (LOVATO, 2010a, p. 125). No caso das imagens do artigo científico, portanto, elas não são recontextualizadas com o mesmo nível de abstração pelas notícias analisadas, corroborando estudos anteriores da recontextualização do discurso verbal da esfera da ciência.

Conforme Van Leeuwen (2005, p. 168), quanto mais uma imagem lembra o modo como algo poderia ser visto na realidade, de um ponto de vista específico e sob condições especificas de iluminação, mais alta a modalidade naturalística. Mas somente as imagens 3, 5 e 7 apresentam modalidade naturalística alta. A Imagem 3 é de uma notícia do próprio site da revista acadêmica que publica o artigo recontextualizado, retratando uma das pesquisadoras no ambiente da pesquisa, que se refere à vida nas cidades modernas e seu impacto no estresse neural social humano. Correlacionado à Imagem 3, o título dessa notícia torna-se o mais objetivo e o único que não menciona o estresse ou refere-se a ele de alguma maneira. Nos títulos das notícias com as imagens 5 e 7 também é mencionada a vida na cidade e sua relação com a atividade cerebral humana, mas essa cidade é retratada de maneira diferente. A cidade da 
Imagem 5, cujo título da notícia pergunta se a vida na cidade poderia mudar nosso cérebro para pior, é grande e repleta de arranha-céus. A cidade da Imagem 7, cujo título da notícia também é uma pergunta, é orgânica e diurna, mostrando céu e água límpidos. A Imagem 7 , portanto, está em aparente contradição com a indagação do título sobre a vida na cidade estar associada ao estresse social. Entretanto, essas três imagens de alta modalidade naturalística têm em comum, além da luminescência: valor, saturação, pureza e diferenciação baixos; temperatura fria; modulação alta; sem fosforescência e brilho; e, apesar de leve transparência na Imagem 7 , todas tendem à opacidade.

As imagens 1, 4 e 6 são naturalístico-sensoriais, onde o visual pode provocar certo efeito de prazer ou desgosto. Nessas, amplia-se o naturalismo: forma, cor, profundidade, luz, sombra, etc. tornam-se mais que reais (VAN LEEUWEN, 2005, p. 170). A modalidade sensorial aparece em contextos que tentam criar uma experiência análoga a uma espécie de sonho (VAN LEEUWEN, 2005, p. 170). Na Imagem 1 há um homem visto de costas aparentando refletir em meio a uma cidade que brilha sob luzes noturnas à sua frente. $\mathrm{O}$ próprio título da notícia da Imagem 1, trocadilho com as palavras "cidade" e "insanidade", pode ser interpretado como um convite à percepção do leitor-internauta. Já a Imagem 4 parece reproduzir o estresse da cidade do título da notícia onde se destaca: é dia e as pessoas são retratadas de modo a aparentar que se movimentam rapidamente (a fotografia está propositalmente "tremida", desfocada). A Imagem 6 igualmente parece convidar ao movimento, mas, seguindo-se o título dessa notícia, assemelha-se a um movimento cerebral em meio a uma cidade noturna e iluminada por coloridos faróis de carros em movimento por entre gigantescos outdoors. A objetividade do título da notícia com a Imagem 6 (em português, "Este é o seu cérebro na cidade"), então, é apenas aparente. Nessas três imagens naturalístico-sensoriais, luminescentes e translúcidas, a modulação é alta e a pureza é média ou alta (Imagem 4). Nas imagens 1 e 6, fosforescência e brilho são altos, mas esses não existem na Imagem 4. O valor é alto nas imagens 1 e 6, mas não na Imagem 4, talvez por ser uma fotografia diurna. A saturação é alta nas imagens 4 e 6 , mas é média na Imagem 1. A temperatura é quente na Imagem 6, mas a Imagem 1 tende ao frio e a Imagem 4 é média. A diferenciação é baixa na Imagem 1, média na Imagem 4 e alta na Imagem 6.

Finalmente, somente as imagens 2 e 8 apresentam modalidade naturalístico-abstrata, o que as aproxima das imagens do artigo científico. A modalidade abstrata, além de ser comum em imagens científicas, também o é na arte moderna, e, quando combinada à naturalística, iluminação, nuances de cor ou outros detalhes criam diferenças individuais irrelevantes para a verdade da imagem (VAN LEEUWEN, 2005, p. 168). O título da notícia da Imagem 2 pergunta se viver na cidade nos torna loucos, e nela aparece uma cidade noturna onde destacam-se coloridos neons, quase como uma pintura. A Imagem 2 é fosforescente e brilhosa, de temperatura média, diferenciação alta e com baixa pureza. As imagens 2 e 8 têm em comum valor, saturação e modulação altos, além de serem um pouco translúcidas. Todavia, a Imagem 8, cujo título da notícia fala sobre viver na cidade, estresse e risco para o nosso cérebro, é bem fria, quase totalmente em tons cinzas, com pureza alta, baixa diferenciação e sem fosforescência e brilho. Van Leeuwen $(2005$, p. 168) destaca que, como atualmente a cor é norma, imagens em preto e branco têm baixa modalidade naturalística e são usadas para representar sonhos, fantasias, etc. Essa imagem naturalístico-abstrata é a que mais se aproxima das imagens do artigo científico. Os índices de saturação, pureza, fosforescência, brilho, temperatura e diferenciação são praticamente os mesmos na Imagem 8 e nas imagens do artigo.

Os parâmetros de traços distintivos analisados nas imagens das notícias de popularização da ciência on-line estão representados graficamente no Quadro 3. 
CASA, Vol.11 n.2, dezembro de 2013

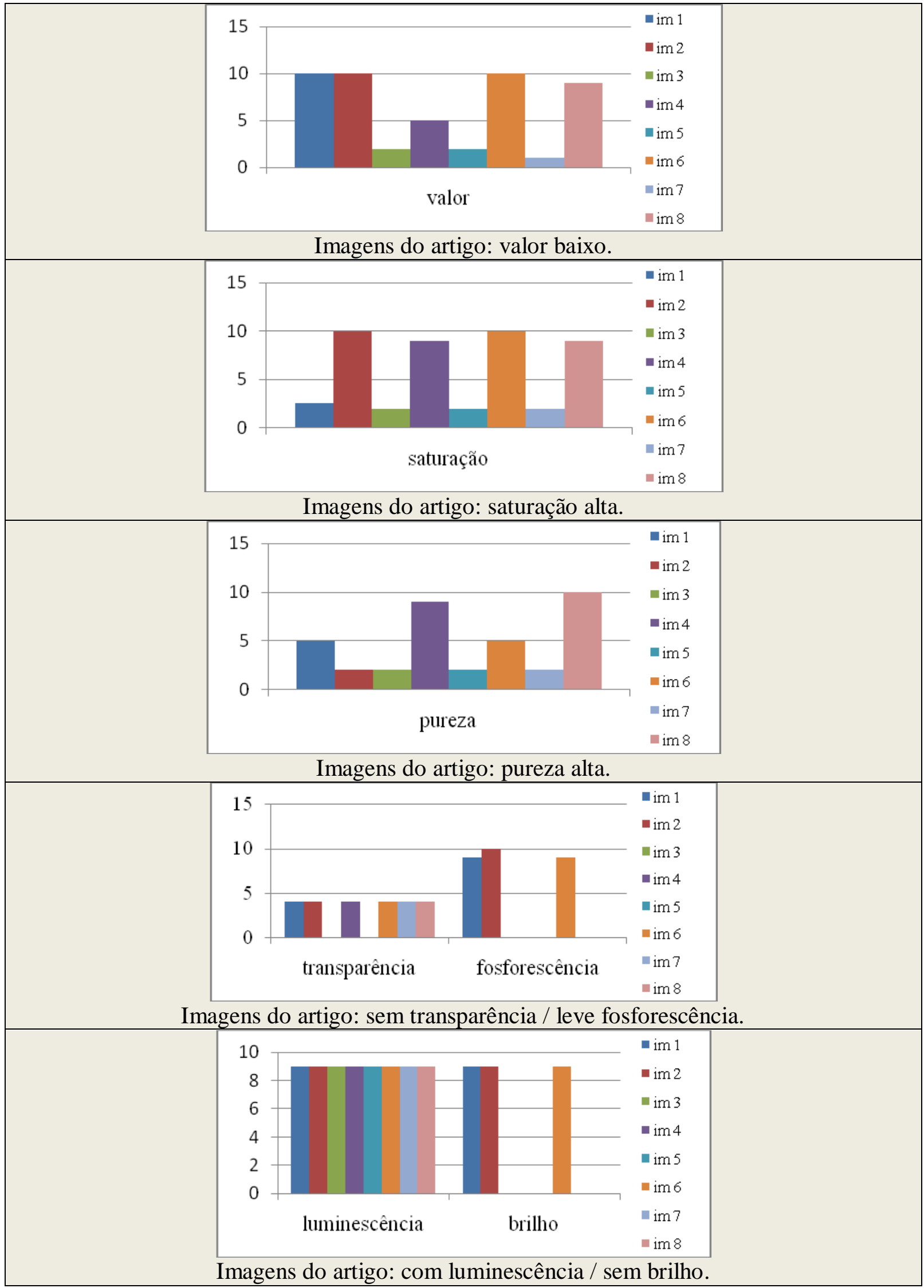

Disponível em: http://seer.fclar.unesp.br/casa 


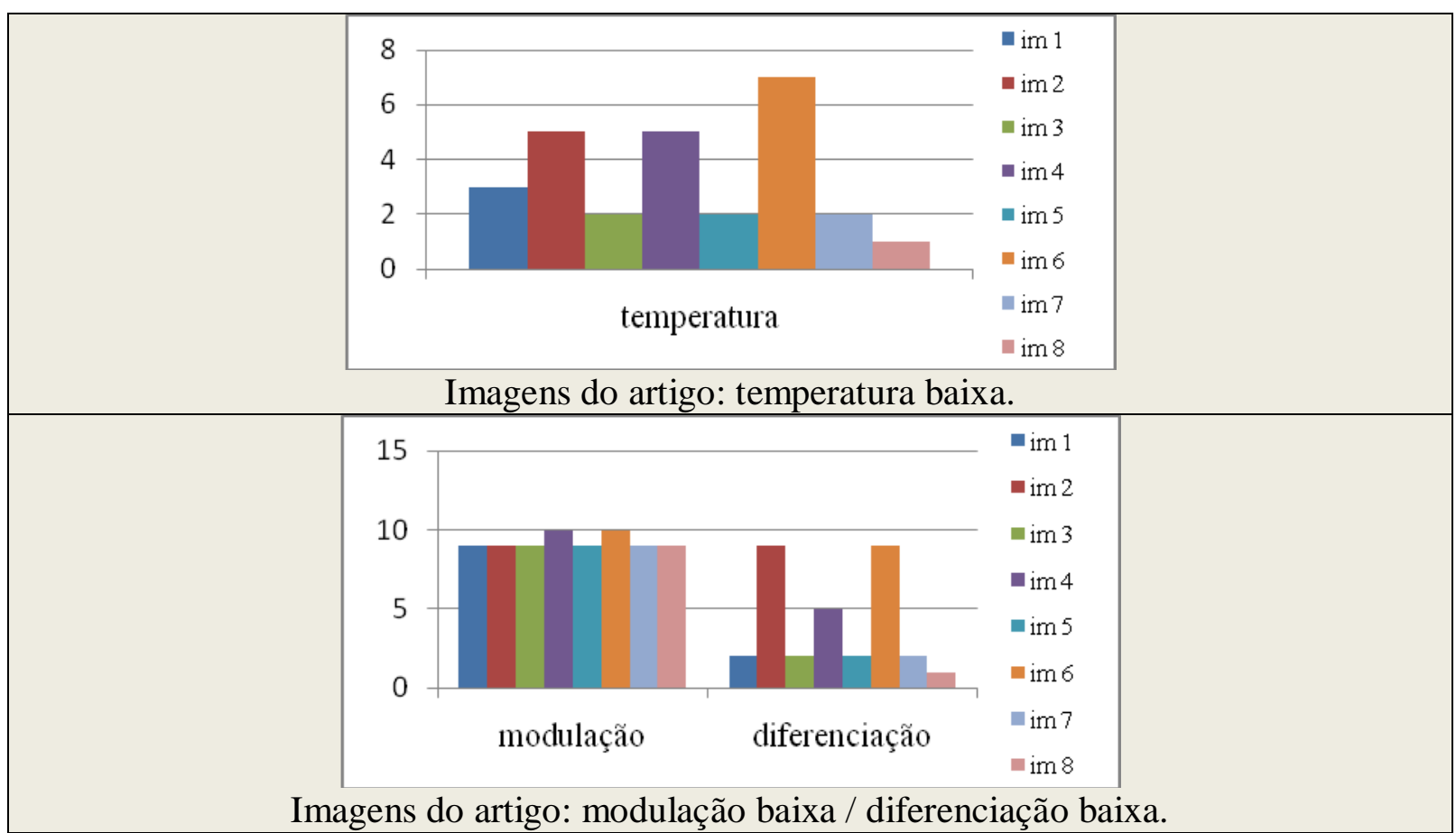

Quadro 3 - Gráficos dos parâmetros analisados nas imagens das notícias de popularização da ciência on-line comparados às imagens do artigo.

Os índices paramétricos de cor analisados nas imagens, conforme suas respectivas modalidades, estão resumidos no Quadro 4.

\begin{tabular}{|c|c|c|c|c|c|c|c|c|c|}
\hline $\begin{array}{c}\text { Imagens } \\
\Rightarrow\end{array}$ & abstratas & \multicolumn{4}{c|}{ naturalísticas } & \multicolumn{2}{c|}{ naturalístico-sensoriais } & \multicolumn{2}{c|}{$\begin{array}{c}\text { naturalístico- } \\
\text { abstratas }\end{array}$} \\
\hline VALOR & artigo & 3 & 5 & 7 & 1 & 4 & 6 & 2 & 8 \\
\hline baixo & baixo & baixo & baixo & alto & médio & alto & alto & alto \\
\hline SATURAÇÃO & alta & baixa & baixa & baixa & baixa & alta & alta & alta & alta \\
\hline PUREZA & alta & baixa & baixa & baixa & média & alta & média & baixa & alta \\
\hline TRANSPAR. & não & não & não & média & média & média & média & média & média \\
\hline FOSFOR. & baixa & não & não & não & alta & não & alta & alta & não \\
\hline LUMIN. & sim & sim & sim & sim & sim & sim & sim & sim & sim \\
\hline BRILHO & não & não & não & não & alto & não & alto & alto & não \\
\hline TEMPER. & baixa & média & média & média & média & alta & alta & alta & baixa \\
\hline MODUL. & baixa & alta & alta & alta & alta & alta & alta & alta & alta \\
\hline DIFERENC. & baixa & média & média & média & média & alta & alta & alta & baixa \\
\hline
\end{tabular}

Quadro 4 - Resumo dos índices paramétricos de cor analisados nas imagens, conforme suas respectivas modalidades.

Os índices de valor, saturação, fosforescência e brilho diferiram muito no conjunto total das oito imagens e não se mostraram relevantes nesta análise. Entretanto, todas as imagens das notícias recontextualizadoras têm modulação alta, característica da modalidade naturalística, ao contrário das imagens abstratas do artigo científico.

Todas as imagens naturalístico-sensoriais são um pouco translúcidas (leve transparência), e, à exceção das imagens 3 e 5, as outras imagens das notícias de popularização da ciência on-line também o são. Isso também pode ser explicado pelo fato do 
suporte ser a tela do computador, um meio onde a cor se torna menos material e mais luminosa e etérea, transformando e sendo transformada pela cor, confundindo-se com a imagem (VAN LEEUWEN, 2011, p. 64).

A pureza só é alta em duas das imagens das notícias de popularização da ciência (Imagem 4 e Imagem 8) e nas do artigo. De acordo com Kress e Van Leeuwen (2002, p. 356), a escala de pureza é cerne da teoria da cor desenvolvida nos últimos séculos. O "esquema de cores de Mondrian", com seus puros vermelhos, azuis e amarelos, tornou-se um significantechave da modernidade; e o esquema de cores pálidas e cianos tornou-se um significante das ideologias pós-modernas, com o hibridismo positivamente valorizado (KRESS; VAN LEEUWEN, 2002, p. 356).

Cinco das oito imagens das notícias de popularização da ciência on-line tem baixa (Imagem 8) ou média-baixa diferenciação (Imagem 1, Imagem 3, Imagem 5 e Imagem 7), inclusive as do artigo recontextualizado. Dependendo do contexto, baixa diferenciação pode significar timidez (KRESS; VAN LEEUWEN, 2002, p. 357; VAN LEEUWEN, 2011, p. 65). Como trata-se do contexto científico, esse achado pode ser considerado previsível.

Finalmente, apesar de a linguagem científica favorecer abstrações, tornando-se um tanto mistificadora aos leitores leigos (FAIRCLOUGH, 2001, p. 223), as imagens naturalístico-abstratas (Imagem 2 e Imagem 8) das notícias analisadas só têm em comum com as imagens abstratas do artigo científico a saturação alta, embora a Imagem 8 seja a que, dentre todas, mais se aproxima às imagens do artigo. Para Kress e Van Leeuwen (2002, p. 356), alta saturação expressa sentimento máximo, positividade e exuberância. Entretanto, alta saturação não foi a regra, e, à exceção da Imagem 6, todas as outras imagens tendem à temperatura fria. A extremidade azul é associada à frieza e distância (KRESS; VAN LEEUWEN, 2002, p. 357), qualidades que se ligam à interpretação do tema do artigo, "vida nas cidades contemporâneas", pelas notícias.

\section{Conclusões}

A literatura recente tem enfatizado que "o empoderamento semiótico depende também da compreensão de semioses não verbais" (MOTTA-ROTH; HENDGES, 2010, p. 43). A estrutura dos textos em revistas, websites e outras mídias modernas não está marcada por palavras, mas pelo layout, cores e tipografia, sem as quais poderiam tornar-se incompreensíveis (VAN LEEUWEN, 2011, p. 92). Conforme Motta-Roth e Hendges (2010, p. 61), em uma sociedade caracterizada por vários contextos de atividade e comunicação, novos registros, gêneros e discursos obrigam a se repensar o conceito tradicional de leitura.

As imagens da esfera científica apresentam aqui modalidade abstrata, dificultando a compreensão imediata ao leitor não especialista. Já todas as imagens da esfera midiática analisadas apresentam modalidade naturalística, em maior ou menor grau. A modalidade naturalística explica a alta modulação de cor em todas essas imagens de notícias de popularização da ciência. Cor modulada, ao contrário de lisa, não expressa uma verdade abstrata (VAN LEEUWEN, 2011, p. 64). Modulação alta é um recurso para mostrar cores específicas (KRESS; VAN LEEUWEN, 2002, p. 357), e pode significar tanto sutileza como excesso de detalhes (VAN LEEUWEN, 2011, p. 64). De acordo com Kress e Van Leeuwen (2006, p. 50 apud MOTTA-ROTH; HENDGES, 2010, p. 58), nessas imagens de cunho fotográfico, há sempre "abundância de detalhes" que também representam alguma coisa, mas a verificação desses detalhes por meio das metafunções composicional, representacional e interpessoal propostas na GVD não foi feita aqui. As cores das imagens de modalidade 
abstrata do artigo científico, por outro lado, apresentam todas baixa modulação e são lisas. Isso pode representar o estilo visual dessas duas esferas de atividade.

$\mathrm{Na}$ popularização da ciência da esfera midiática jornalística, os jornalistas são mediadores da interação entre cientistas e público (Cf. BEACCO et al., 2002). O estilo está relacionado às interações com os outros, à metafunção interpessoal, a significados textuais identificacionais (Cf. FAIRCLOUGH, 2003) e à entonação expressiva do gênero preparada pelas estruturas composicional e temática (Cf. BAKHTIN, 1997). O estilo dessa ordem discursiva representa, consequentemente, as identidades dos participantes da interação em seus aspectos linguísticos e semióticos (Cf. FAIRCLOUGH, 2003), sendo um deles o leitor não especialista. $O$ fato de todas as imagens das notícias de popularização da ciência analisadas apresentarem modalidade naturalística pode ser porque o anúncio de uma descoberta da ciência a leitores não especialistas "envolve a comunicação de fatos que possam ser facilmente visualizados pelo leitor não familiarizado com a investigação científica" (PAGANO, 1998, p. 61 apud LOURENÇO, 2010, p. 20). No presente artigo, a análise linguística/semiótico-social e interdiscursiva das cores de imagens de popularização da ciência, quanto à função interpessoal/identificacional, também permite a percepção de atos de cores (Cf. KRESS; VAN LEEUWEN, 2002). Em relação aos atos de cores, à exceção da Imagem 3 e da Imagem 7, ambas com alta modalidade naturalística, todas as outras imagens conduzem o leitor-internauta a um tipo de estresse visual, forma de materializar o tema apresentado no título do artigo científico. Nesse caso, a interação entre jornalistas/instituições midiáticas e leitores-internautas é percebida na intenção dos primeiros em aumentar os níveis de estresse nos últimos (Cf. KRESS; VAN LEEUWEN, 2002).

Em adição, à exceção de valor e modulação altos e leve transparência, a Imagem 8 , com modalidade naturalístico-abstrata, justamente é a que mais se aproxima das imagens abstratas do artigo científico recontextualizado também quanto aos traços distintivos. Entretanto, para esse dado revelar-se significativo, o corpus com imagens apresentando esse tipo de julgamento visual por parte da instituição social midiática teria de ser ampliado.

Outro dado relevante é que as imagens das notícias com alta modalidade naturalística (Imagem 3, Imagem 5 e Imagem 7) têm os mesmos parâmetros distintivos: modulação alta e baixos índices de valor, saturação, pureza, transparência (bem leve na Imagem 7), luminosidade, brilho, temperatura, diferenciação e luminescência. Isso pode indicar um tipo de "esquema de cores" para essa modalidade. Escolher um design implica em selecionar um esquema de cores que talvez seja mais importante do que uma tonalidade como operador de significado (KRESS; VAN LEEUWEN, 2002, p. 349-350). Todos os esquemas de cores vivem além de seu período histórico como recursos semióticos reconhecidos que podem continuar a ser usados e combinados para sinalizar posições ideológicas diferentes, postulam Kress e Van Leeuwen (2002, p. 366).

Sendo assim, a análise de imagens por meio da Semiótica da Cor (KRESS; VAN LEEUWEN, 2002; VAN LEEUWEN, 2011), como evidência de uma ideologia institucional subjacente, ajuda na identificação de marcas intertextuais implícitas ou de interdiscursividade no processo de recontextualização do discurso científico. Quando a voz do outro é incorporada ao texto, verbal ou não verbal, sempre haverá escolhas sobre como estruturá-las, como e onde incorporá-las ao texto (FAIRCLOUGH, 2003, p. 53). A atividade crítica consiste, essencialmente, em tornar visível a natureza interligada das coisas (FAIRCLOUGH, 1985, p. 747).

No entanto, este é um estudo embrionário e os dados levantados servirão de apoio para pesquisas futuras acerca do funcionamento da esfera midiática jornalística digital de popularização da ciência, ampliando-se o corpus e correlacionando-se texto verbal e não 
verbal. A cor não existe por conta própria (KRESS; VAN LEEUWEN, 2002, p. 351), e, além dela, todas as escolhas composicionais, como design, layout, links, sons, e palavras, são significativas para uma análise crítica do discurso on-line. Os significados da palavra e da imagem, por exemplo, não são aditivos, mas multiplicativos, um se modifica em função do outro, "fazendo do todo algo maior do que a soma das partes" (LEMKE, 2010, p. 456). Lemos textos e interpretamos imagens efetivamente em função da presença uns do outros, pois os gêneros do letramento "combinam imagens visuais e texto impresso em formas que tornam as referências entre eles essenciais para entendê-los" (LEMKE, 2010, p. 455).

\section{AGRADECIMENTOS}

A autora agradece as Professoras Dr. ${ }^{a}$ Graciela Rabuske Hendges e Dr. ${ }^{a}$ Désirée Motta-Roth, do Laboratório de Pesquisa e Ensino de Leitura e Redação da Universidade Federal de Santa Maria (LABLER/UFSM), pelas sugestões acerca da teoria aqui abordada.

\section{REFERÊNCIAS}

AUTHIER-RÉVUZ, J. Hétérogénéité montreee et hétérogénéité constitutive: éléments pour une approche de l'autre dans le discours. DRLAV: Revue de linguistique, Paris, v. 26, p. 91 $151,1982$.

BAKHTIN, M. M. Estética da Criação Verbal. Tradução a partir do francês de Maria Ermantina Galvão G. Pereira. 2. ed. São Paulo: Martins Fontes, 1997.

BAKHTIN, M. M. The dialogic imagination. Tranlated by Caryl Emerson and Michael Holquist. Austin: University of Texas Press, 1981.

BEACCO, J.-C.; CLAUDEL, C.; DOURY, M.; PETIT, G.; REBOUL-TOURÉ, S. Science in media and social discourse: new channels of communication, new linguistic forms. Discourse Studies, New York/London, v. 4, n. 3, p. 277-300, 2002.

BERNSTEIN, B. A estruturação do discurso pedagógico: classe, códigos e controle. Tradução de Tomaz Tadeu da Silva e Luiz Fernando Gonçalves Pereira. Petrópolis: Vozes, 1996.

BERNSTEIN, B. The structuring of pedagogic discourse. New York/London: Routledge, 1990.

CANAVILHAS, J. Webjornalismo. Da pirâmide invertida à pirâmide deitada. In: Biblioteca on-line de ciências da comunicação. Covilhã, Faculdade de Comunicação, Universidade da Beira Interior, 2006. [on-line] Disponível em: <http://www.bocc.ubi.pt/_listas/tematica.php?codtema=94>. Acesso em: 27 dez. 2012.

CALSAMIGLIA, H.; LÓPES FERRERO, C. Role and position of scientific voices: reported speech in the media. Discourse Studies, New York/London, v. 5, n. 2, p. 147-173, 2003.

CHARTERIS-BLACK, J. Corpus approaches to critical metaphor analysis. London: Palgrave Macmillan, 2004.

CHOULIARAKI, L.; FAIRCLOUGH, N. Discourse in late modernity: rethinking Critical Discourse Analysis. Edinburgh: Edinburgh University Press, 1999.

COPE, B.; KALANTZIS, M. Multiliteracies: the beginnings of an idea. In: COPE, B.; KALANTZIS, M. (Orgs.). Multiliteracies: literacy learning and the design of social futures. New York/London: Routledge, 2000, p. 3-8.

DIONÍSIO, Â. P. Gêneros multimodais e multiletramento. In: KARWOSKI, A. M.; GAYDECZKA, B.; BRITO, K. S. (Org.) Gêneros textuais: reflexões e ensino. 2. ed. Rio de Janeiro: Lucerna, 2005, p. 159-177. 
FAIRCLOUGH, N. Analysing discourse: textual analysis for social research. New York/London: Routledge, 2003.

FAIRCLOUGH, N. Critical and descriptive goals in discourse analysis. Journal of Pragmatics, Elsevier Publishing Group, v. 9, n. 6, p. 739-763, 1985.

FAIRCLOUGH, N. Discurso e mudança social. Tradução de Isabel Magalhães et al. Brasília: Editora da UnB, 2001.

FAIRCLOUGH, N. Linguistic and Intertextual Analysis within Discourse Analysis. In: JAWORSKI, A.; COUPLAND, N. (Eds.) The Discourse Reader. New York/London: Routledge, 2000.

FAIRCLOUGH, N. Media discourse. New York: Edward Arnold, 1995.

FAIRCLOUGH, N. Multiliteracies and language: orders of discourse and intertextuality. In: COPE, B.; KALANTZIS, M. (Eds.) Multiliteracies: literacy learning and the design of social futures. New York/London: Routledge, 2006, p. 162-181.

FERREIRA, A. B. H. Novo dicionário Aurélio da língua brasileira. 2. ed. Rio de Janeiro: Nova Fronteira, 1986.

FIORIN, J. L. Introdução ao pensamento de Bakhtin. São Paulo: Ática, 2006.

FOUCAULT, M. What is enlightenment? In: RABINOW, P. (Ed.) Michel Foucault: Essential Works. Vol. 1 (Ethics). Harmondsworth: Penguin, 1994, p. 303-319.

GERHARDT, L. B. A representação dos atores sociais e o processo de reformulação em notícia de popularização científica. In: MOTTA-ROTH, D.; GIERING, M. E. (Org.) Discursos de popularização da ciência. Santa Maria: PPGL Editores, 2009, p. 63-70.

HALLIDAY, M. A. K. An introduction to functional grammar. London: Edward Arnold. 1985.

HALLIDAY, M. A. K.; MATTHIESSEN, C. M. I. M. An introduction to functional grammar. London: Arnold, 2004.

HEYVAERT, L. Nominalization as grammatical metaphor. In: SIMON-VANDENBERGEN, A-M; TAVERNIERS, M.; RAVELLI, L. J. (Org.) Grammatical metaphor: views from Systemic Functional Linguistics. Amsterdam/Philadelphia: John Benjamins, 2003, p. 65-99.

IVANISSEVICH, A. A mídia como intérprete. In: VILAS BOAS, S. (Org.) Formação \& informação científica: jornalismo para iniciador e leigos. São Paulo: Summus, 2005, p. 1330.

KRESS, G.; VAN LEEUWEN, T. Colour as a semiotic mode: notes for a grammar of colour. Visual communication, London, v. 1, n. 3, p. 343-368, 2002.

KRESS, G.; VAN LEEUWEN, T. Reading images. The grammar of visual design. 2. ed. New York/London: Routledge, 2006.

KRISTEVA, J. La révolution du langage poétique. L'avantgarde a la fin du XIXe. Siècle: Lautréamont et Mallarmé. Paris: Seuil, 1974.

KUHN, T. S. The structure of scientific revolution. Chicago: The University of Chicago Press, 1962/1970.

LAGE, N. A estrutura da notícia. 5. ed., São Paulo: Ática, 2005.

LAKOFF, G.; JOHNSON, M. Metáforas da Vida Cotidiana. Tradução de Mara Sophia Zanotto et al. Campinas: Mercado de Letras. São Paulo: Educ, 2002.

LEDERBOGEN, F.; KIRSCH, P.; HADDAD, L.; STREIT, F.; TOST, H.; SCHUCH, P.; WÜST, S.; PRUESSNER, J. C.; RIETSCHEL, M.; DEUSCHLE, M.; MEYERLINDENBERG, A. City living and urban upbringing affect neural social stress processing in humans. Nature, Nature Publishing Group, v. 474, p. 498-501, 2011. 
LEMKE, J. L. Letramento metamidiático: transformando significados e mídias. Tradução de Clara Dornelles. Trabalhos em Linguística Aplicada, Campinas, v. 49, n. 2, p. 455-479, 2010.

LITTLEMORE, J.; LOW, G. Metaphoric competence. Second language learning, and communicative language ability. Applied Linguistics, Oxford, v. 7, n. 2, p. 268-294, 2006. LOURENÇO, R. S. Metáforas lexicais em estruturas verbais e mentais em notícias de popularização da ciência. 2010. 95 f. Dissertação (Mestrado em Letras - Estudos Linguísticos) - Universidade Federal de Santa Maria, Santa Maria.

LOVATO, C. S. Análise das imagens em notícias de popularização científica. Travessias, Cascavel, v. 4, p. 114-133, 2010a.

Análise de gênero: investigação da organização retórica de notícias de popularização da ciência na revista Ciência Hoje On-line. 2010b. 102 f. Dissertação (Mestrado em Letras Estudos Linguísticos) - Universidade Federal de Santa Maria, Santa Maria.

LOTZ, A. D. The television will be revolutionized. New York/London: New York University Press, 2007.

MAINGUENAU, D. Nouvelles tendances en analyse du discours. Paris: Hachette, 1987.

MARTIN, J. R. English text: systems and structure. Philadelphia/Amsterdam: John Benjamins, 1992.

MILLER, T. Visual persuasion: a comparison of visual in academic texts and the popular press. English for Specific Purposes, Elsevier Publishing Group, v. 17, n. 1, p. 29-46, 1998.

MOTTA-ROTH, D. Sistemas de gêneros e recontextualização da ciência na mídia eletrônica. Gragoatá, Niterói, v. 1, n. 28, p. 153-174, 2010.

Últimas descobertas! Estrutura potencial do gênero notícia de popularização da ciência. In: Simpósio Internacional de Estudos de Gêneros Textuais, V, ago. 2009, Caxias do Sul, RS. Anais. Caxias do Sul: EDUCS, 2009, p. 86-87.

MOTTA-ROTH, D.; HENDGES, G. R. Explorando modalidades retóricas sob a perspectiva da multimodalidade. Letras, Santa Maria, v. 20, n. 40, p. 43-66, 2010.

MOTTA-ROTH, D.; LOVATO, C. S. O poder hegemônico da ciência no discurso de popularização científica. Calidoscópio, São Leopoldo, v. 9, n. 3, p. 251-268, 2011.

MOTTA-ROTH, D.; MARCUZZO, P. Ciência na mídia: análise crítica de gênero de notícias de popularização científica. Revista Brasileira de Linguística Aplicada, Belo Horizonte, v. 10, n. 3, p. 511-538, 2010.

MOTTA-ROTH, D.; SCHERER, A. Expansão e contração dialógica na mídia: intertextualidade entre ciência, educação e jornalismo. DELTA, São Paulo, v. 28, n. esp., p. 639-672, 2012.

MYERS, G. Discourse studies of scientific popularization: questioning the boundaries. Discourse Studies, New York/London, v. 5, n. 2, p. 265-279, 2003.

NOVELINO, M. O. Gramática Sistêmico-Funcional e o estudo de imagens em livro didático de inglês como língua estrangeira. In: International Systemic Functional Congress, 33, jul. 2006, São Paulo. Proceedings. São Paulo: LAEL/PUC-SP, 2006, p. 315-330.

PAGANO, A. S. Genes, ovelhas e discos compactos: alguns aspectos das reescritas de descobertas científicas. In: MACHADO, I. L.; CRUZ, A. R.; LYSARDO-DIAS, D. Teorias e práticas discursivas. Estudos em análise do discurso. Belo Horizonte: Editora da UFMG/Carol Borges, 1998, p. 55-72.

PAGANO, A.; MAGALHAES, C. Análise crítica do discurso e teorias culturais: hibridismo necessário. DELTA, São Paulo, v. 21, n. esp., p. 21-43, 2005. 
PEREIRA, A. O poder da imagem na vulgarização científica. In: SOUSA, C.; MARQUES, N.; SILVEIRA, T. (Orgs.) A comunicação pública na ciência. Taubaté: Cabral Editora e Livraria Universitária, 2003, p. 139-147.

PERNÃO, J. N. O léxico da cor. In: Laboratório da Cor. Lisboa, Faculdade de Arquitectura - UTL - Universidade de Lisboa, 2005-2006. [on-line] Disponível em: <http://apcor.org/pt/imagens/proj_dec/proj_pernao.pdf>. Acesso em: 21 ago. 2013.

PIRES, V. L.; TAMANINI-ADAMES, F. A. Desenvolvimento do conceito bakhtiniano de polifonia. Estudos Semióticos, São Paulo, v. 6, n. 2, p. 66-76, 2010.

RAMALHO, V.; RESENDE, V. M. Análise de Discurso (para a) Crítica: o texto como material de pesquisa. Campinas: Pontes, 2011.

RESENDE, V. M. Análise de Discurso Crítica e Realismo Crítico: implicações interdisciplinares. Campinas: Pontes, 2009a.

Análise discursiva crítica do uso de metáforas em uma interação etnográfica no movimento nacional de meninos e meninas de rua. Revista da ABRALIN, Natal, v. 8, n. 1, p. $125-148,2009$ b.

RICOEUR, P. La métaphore et le ploblème central de l'herméunetique. Revue philosophique de Louvain, Louvain, n. 70, p. 93-112, 1975.

SANTOS, F. R. S.; SOUZA, M. Aspectos multimodais em editoriais da Veja. In: Simpósio Hipertexto e Tecnologias na Educação, 2, set. 2008, Recife. Anais. Recife: NEHTE-UFPE, 2008, p. 1-16.

SARDINHA, T. B. Metáfora. São Paulo: Parábola, 2007.

SOARES, M. Novas práticas de leitura e escrita: letramento na cibercultura. Educação \& Sociedade, Campinas, v. 23, n. 81, p. 143-160, dez. 2002.

TAMANINI-ADAMES, F. A.; LOVATO, C. S. Intertextualidade como recontextualização. Linguagem - Estudos e Pesquisas, Catalão, v. 15, n. 2, p. 203-224, 2011.

TAVERNIERS, M. Grammatical metaphors in English. Moderna språk, Gothenburg, v. 98, n. $1, \quad$ p. 17-26, 2004. Disponível em: <http://users.ugent.be/ mtaverni/pdfs/Taverniers_2004_GrammaticalMetaphors-PP.pdf>.

Acesso em: 29 ago. 2013.

THOMPSON, G. Introducing functional grammar. $2^{\text {nd }}$ ed. London: Arnold, 2004.

TILIO, R. C. Revisitando a Análise Crítica do Discurso: um instrumental teóricometodológico. E-scrita, Rio de Janeiro, v. 1, n. 2, p. 86-102, 2010.

UNSWORTH, L. Teaching multiliteracies across the curriculum. Changing contexts of text and image in classroom practice. Buckinghan/Philadelphia: Open University Press, 2001. VAN LEEUWEN, T. Introducing social semiotics. New York/London: Routledge, 2005.

The language of colour. An introduction. New York/London: Routledge, 2011.

VASQUES, C. M. Uma sinfonia intertextual: cinema, quadrinhos e televisão - uma composição de futuro presente em Reinações de Narizinho, de Monteiro Lobato. Terra Roxa e outras terras, Londrina, v. 11, n. 1 (131), p. 20-27, 2007.

VIAN JR., O. O sistema de avaliatividade e os recursos para gradação em Língua Portuguesa: questões terminológicas e de instanciação. DELTA, São Paulo, v. 25, n. 1, p. 99-129, 2009.

VIEIRA, W. M. A metáfora e sua função persuasiva em artigos de opinião sob a perspectiva da linguística sistêmico-funcional. 2008. 116 f. Dissertação (Mestrado em Linguística Aplicada e Estudos da Linguagem) - Pontifícia Universidade Católica de São Paulo, São Paulo.

VILELA, M. A metáfora na instauração da linguagem: teoria e aplicação. Línguas e Literaturas, Porto, n. XIII, p. 317-356, 1996. Disponível em:<http://ler.letras.up.pt/uploads/ficheiros/2741.pdf>. Acesso em: 21 ago. 2013. 
CASA, Vol.11 n.2, dezembro de 2013

WARD, M. O que é jornalismo online? In: WARD, M. Jornalismo online. Tradução de Moisés Santos, Silvana Capel dos Santos e Tatiana Gerasimczuk Castellani. São Paulo: Roca, 2007, p. 1-29.

XAVIER, A. C. A era do hipertexto: linguagem e tecnologia. Recife: Editora Universitária UFPE, 2009. 